\title{
Prospects for using aluminum matrix composite materials in the automotive industry
}

\author{
Ivan Romanov ${ }^{1,{ }^{*}}$ Elena Romanova ${ }^{1}$, and Evgeny Chernyshov ${ }^{1}$ \\ ${ }^{1}$ Nizhny Novgorod State Technical University n.a. R.E. Alekseev, 603950, Nizhny Novgorod, Minin \\ st. 24, Russia
}

\begin{abstract}
The scope of the use of aluminum-alloy-based metal-matrix composite materials has been expanding in recent years. However, the high cost of raw materials is a considerable deterrent to the widespread implementation of products made of such composites. Therefore, the ranges of the said materials commercial application are yet inadequate to their technical and operational capabilities. So, methods of making metalmatrix composite materials directly from a liquid melt are currently of interest. This paper presents the theoretical studies and the results of practical experiments for the production of metal-matrix composite material by the internal oxidation method. There are described the results of mechanical tests and the microstructure of specimens confirming theoretical assumptions in the oxidation of aluminum melt array. A comparative analysis is given for the cost of producing an alloy containing $30 \%$ of $\mathrm{Al}_{2} \mathrm{O}_{3}$ particles obtained by adding the $\mathrm{Al}_{2} \mathrm{O}_{3}$ powder and an alloy obtained by the internal oxidation of the aluminum melt. The studied technology provides for the formation of aluminum oxide directly in the aluminum melt, thus enabling to produce a composite material by a singlestage process and ensuring the process efficiency.
\end{abstract}

\section{Introduction}

Aluminum alloys were first used by Kenworth as a material of major components for truck frames over 60 years ago. To reduce the front axle assembly with brakes and suspension, International Harvester was in 1974 the world-first designer of a front axle beam made of aluminum alloy. The mounting of aluminum gearbox cases for drive axles was started more than 50 years ago. So, Rockwell Standard launched in 1962 the output of drive axles R-170, cranks of a single hyoid gearbox thereof might be cast from malleable cast iron or aluminum alloy. The difference in prices of the said versions was about $4 \%$. Due to the manufacture of a gearbox case from aluminum the weight of axle R-170 without hubs, wheel bearings, oil seals, brakes and suspension parts is reduced by $8.74 \%$

Nevertheless it is currently not always possible to obtain the desired level of properties when using conventional metallic materials mainly because of their non-compliance with new increased requirements for strength, rigidity and wear resistance. For example, the use of aluminum may reduce the weight of the most heavy engine component - a block of

\footnotetext{
*Corresponding author: nil_st@nntu.ru
} 
cylinders by $50 \%$. A compromise is sought herewith in design between the strength, rigidity and wear resistance on the one hand and the cost and weight on the other. The low wear resistance of ordinary aluminum alloys under high temperature conditions requires the use of cast-iron sleeves or coatings or the creation of special alloys with additional chemical treatment. Higher coefficients of linear thermal expansion force to seek measures for stabilizing gaps between parts. The lack of sleeves requires using aluminum alloy, which would have sufficient wear resistance for working in pairs with a piston and piston rings. Therefore, in the 1970s Mahle developed a method for strengthening aluminum pistons by introducing into melt of short ceramic fibers based on aluminum oxides, carbides and silicon nitrides. The high hardness of particles enables to significantly increase the wear resistance, in particular, grooves of the upper piston ring. Toyota was one among the first to develop couplings made of composite material for an experimental engine designed for the concept car FX-1 (1983).

Aluminum alloy based metal-matrix composite material (MMC) currently find more and more extensive use in the automotive industry as they are distinguished by their higher hard-wearing, high resistance to crack generation, the lower coefficient of linear thermal expansion, improved strength characteristics, heat resistance and thermal conductivity. The main constraints for the extending use of composites are the cost of their fabrication and increasing production expenses [1-5]. Figure 1 shows the fatigue curves of alloy 2080 with varying saturation degree. Figure 2 shows comparative data for wear of specimens from alloys A356, A356 and cast iron.

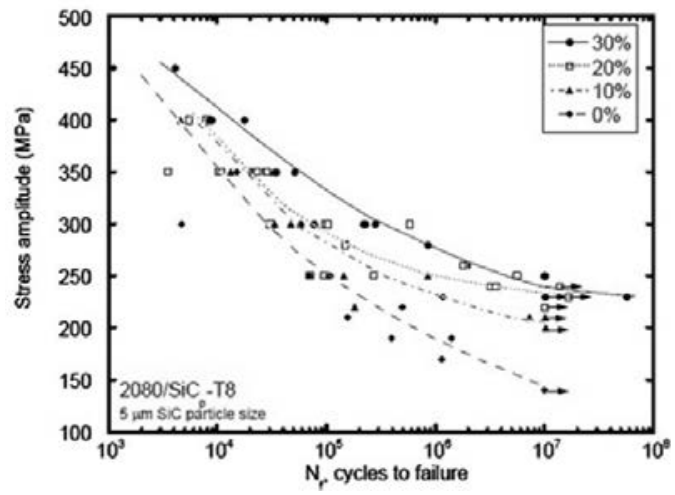

Fig.1. Fatigue curves of alloy 2080 with varying saturation degree [6]

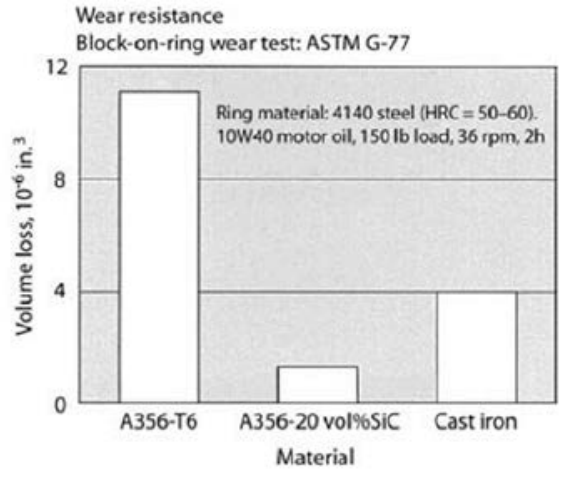

Fig. 2 Volume loss of aluminum alloy, aluminum composite, and cast iron during sliding wear [7]

Aluminum alloy brake drums were first mounted on the Buick and Pontiac vehicle in 1966. The MMC high wear resistance and high thermal conductivity make it possible to substitute cast iron and steel in disc brake rotors and in brake drums, thus reducing the weight to $60 \%[8,9]$. The paper [10] describes the history of the MMC application in automobile brake systems. The typical examples of the MMC use in brake systems are Volkswagen, Audi, Toyota vehicles.

There are known many developments of aluminum composites reinforced with aluminum oxide. However, because of the low adhesion of $\mathrm{Al}_{2} \mathrm{O}_{3}, \mathrm{SiC}$ is used as a disperse filler, which is much more expensive and adds the cost of a product made of composite material. The development of alternative MMC manufacture technologies reducing essentially the cost will significantly extend the scope of the MMC use in the automotive industry. 
Quite a significant reserve for enhancing the strength is the further improvement of metal matrix composite properties, the development of their production technologies [1114]. Not with standing, the cost of aluminum-based MMC is high and only single parts are currently widely used, as distinct from aviation. MMC with reinforcing particles $\mathrm{Al}_{2} \mathrm{O}_{3}$ has an improved complex of mechanical and service properties of the material.

The most typical example of reducing the MMC production cost is the internal oxidation [11]. It enables to reduce the cost of raw materials thereby promoting the wider use of composites.

\section{Practical Studies}

In particular, Table 1 shows the dynamics of heating MCM of the Al-Si chemical composition (7-9\% of $\mathrm{Si}$ and $18-20 \%$ of $\mathrm{Al}_{2} \mathrm{O}_{3}$ ) and $\mathrm{Al}-\mathrm{Si}-\mathrm{Cu}$ (7-9\% of $\mathrm{Si}, 3-6 \%$ of $\mathrm{Cu}$ and $18-24 \%$ of $\mathrm{Al}_{2} \mathrm{O}_{3}$ ) as compared to $\mathrm{C} 424$ at continuous braking depending on the pressure in the "brake disk - block" system.

Table 1. Dynamics of heating at extended braking

\begin{tabular}{|c|c|c|c|c|}
\hline \multirow{2}{*}{ Material* } & \multicolumn{4}{|c|}{ Test period } \\
\cline { 2 - 5 } & 30 seconds & 1 minutes & 2 minutes & 5 minutes \\
\hline \multicolumn{5}{|c|}{ Pressure $25 \mathrm{~kg} / \mathrm{sm}^{2}$} \\
\hline Cast iron C424 & 86,3 & 117 & 147 & 150 \\
\hline MMC Al-Si & 108 & 169 & 238,3 & 287 \\
\hline \multicolumn{5}{|c|}{ Pressure $37.5 \mathrm{~kg} / \mathrm{sm}^{2}$} \\
\hline Cast iron C424 & 97 & 124 & 146 & 160 \\
\hline MMC Al-Si & 163 & 231 & 278 & 322 \\
\hline \multicolumn{7}{|c|}{ Pressure $50 \mathrm{~kg} / \mathrm{sm}^{2}$} \\
\hline Cast iron C424 & 89 & 126 & 147 & 160 \\
\hline MMC Al-Si & 100 & 132 & 168 & 212 \\
\hline MMC Al-Si-Cu & 197 & 255 & 315 & 351 \\
\hline
\end{tabular}

* - no experiments were performed with MMC ASC under the pressure of 25 and

\section{$37.5 \mathrm{~kg} / \mathrm{cm}^{2}$}

From the data presented in Table 1, It follows from data in Table 1 that at extended braking, for example, during the sloping motion a brake system using CЧ 24 provides the smaller heat removal, thus reducing the brake system effectiveness.

A special type of material such as foam aluminum is also currently used in machinery. It is produced by purging gas through a liquid metal or by using various foaming agents. Porous aluminum may have its porosity up to $80 \%$ with the pore size up to $5 \mathrm{~mm}$. The strength and plastic properties of foam essentially depend on its density [15 17]. However, this material has low mechanical properties and some significant constraints for manufacturing complex-shaped components.

Paper [18] describes the study of producing cast bars from aluminum alloy reinforced by introducing hollow aluminosilicate microspheres. The results of microstructural analysis and the study of strength properties are presented. Experiments have been carried out both with conventional microspheres and microspheres coated with chromium and chromium carbide to increase the melt adhesion to the microsphere surface. The effect of adhesion on mechanical properties is shown.

The method of producing aluminum-matrix MMCs saturated with hollow spherical particles enables to obtain a material with improved mechanical properties as compared to basic aluminum alloy. Moreover, due to introducing hollow microspheres a smaller specific density and accordingly the weight of a bar are achieved, thus, allowing to more fully 
implementing MMC potentialities. The strength of the material saturated with metalized microspheres is thereat by $20 \%$ higher than the strength of a material saturated with conventional microspheres [18].

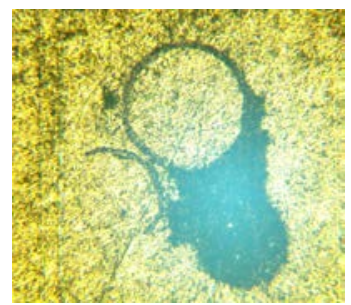

Fig. 3. Specimen with destroyed spheres of over $50 \mu \mathrm{m}$ in size

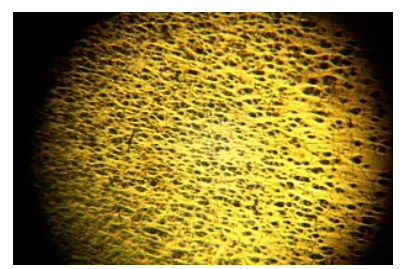

Fig. 4. Specimen with high saturation of microspheres

\section{Conclusions}

The elaboration of alternative MMC manufacturing technologies providing the essential cost reduction will significantly increase the scope of the MMC use in the automotive industry.

The application of the elaborated MMC manufacturing technology based on the oxidation of aluminum with oxygen shall enable to significantly reduce the time and economic costs. Furthermore, depending on a technical assignment and any required operational characteristics quite a wide variability of the strengthening phase is possible without changing the general plant design. Reinforcing particles are synthesized thereat directly in the melt. It makes possible the single-stage manufacturing of composites and achieving the thermodynamic stability, the tight contact and adequate adhesion between the matrix and the strengthening phase.

The described method of producing aluminum-matrix MMC saturated with spherical ceramic particles enables to obtain a material with improved mechanical properties as compared to basic aluminum. Moreover, due to hollow microspheres a smaller specific weight and the mass of a component are achieved, thus, allowing to more fully implementing MMC potentialities

The reported study was funded by RFBR according to the research project № 18-33-00455 мол_а

\section{References}

1. J.E. Allison, G.S. Cole, Metal-matrix Composites in the Automotive Industry: opportunities and challenges. Journal of the Minerals, Metals and Materials Society, 45 (1993)

2. N. Axen, S. Jacobson, A model for the abrasive wear resistance of multiphase, Mater. Wear. 174 (1994)

3. Karakoç, H., Karabulut, Ş., Çıtak, R. Study on mechanical and ballistic performances of boron carbide reinforced $\mathrm{Al} 6061$ aluminum alloy produced by powder metallurgy Composites Part B: Engineering 148 (2018)

4. D. Ramesh, Sand abrasive behavior of aluminium -frit particulate metal matrix composites, International journal of emrging trends in engineering and development, Vol 5, Issue 2, (2012) 
5. C. Honnaiah, Effect of particle size on dry sliding wear of cast $\mathrm{A} 356-\mathrm{Al}_{2} \mathrm{O}_{3}$ Metal matrix composites, International journal of engineering trends and Technology, 12 (2014)

6. Haghsh1enas, Meysam. (2015). Metal-Matrix Composites. Reference Module in Materials Science and Materials Engineering. 10.1016/B978-0-12-803581-8.03950-3.

7. Rohatgi, P.K. \& Gupta, N \& Weiss, D \& Miracle, D. (2006). Synthesis and applications of cast metal matrix composites and syntactic foams. International SAMPE Technical Conference. DOI: 10.1361/asmhba0005339

8. Pradeep Rohatgi, IUNIDO's State-of-the-art series: “Advances in Materials Technology: MONITOR”, Compiled by the Industrial Technology Development Division Department of Industrial Promotion, Vienna, Austria, No.17, Feb. 1990

9. Liu Yao-Hui, Du Jun, Yu Si-rong, Wang Wei High temperature friction and Wear behaviour of Al2O3 and /or Carbon short fibre reinforced Al-12Si alloy Composites Wear, 256 (2004)

10. M. M. Rahman, A. A. Adebisi, M. A. Maleque, Metal Matrix Composite Brake Rotor: Historical Development and Product Life Cycle Analysis. International Journal of Automotive and Mechanical Engineering (IJAME), 4 (2011)

11. E A Chernyshov, A D Romanov, E A Romanova, Production of Highly Reinforced Dispersion-Strengthened Composite Material Based on Aluminum by Internal Oxidation, Metallurgist Volume 62, Issue 7-8 (2018)

12. M. Rijesh, James Valder, D. Jithin, C. R. Dileep, R. N. Abin, F. Shibin, M. M. Havila Production of Al-Al2O3 MMC by P/M Route and to Study the Feasibility of Fusion Welding, American Journal of Materials Science, 6 (2016)

13. Gnanavelbabu, A., Rajkumar, K., Saravanan, P. Investigation on the cutting quality characteristics of abrasive water jet machining of AA6061-B4C-hBN hybrid metal matrix composites Materials and Manufacturing Processes 33 (2018)

14. I Dinaharan, E T Akinlabi, Low cost metal matrix composites based on aluminum, magnesium and copper reinforced with fly ash prepared using friction stir processing, Composites Communications 9 (2018)

15. Kovtunov A.I., Khokhlov Yu.Yu., Myamin S.V. Technology of formation of layered composites of a system a titanium - penoalyuminy. Metallurgist. 4 (2015)

16. Voronin S.V., Loboda P. S. Ways of receiving sponges on the basis of aluminum, News of the Samara scientific center of the Russian Academy of Sciences. T. 18. No. 4-6 (2016)

17. Samuylov S.D., Troitsk O.A. New methods of receiving porous metal materials with the closed and hole content, Fundamental and applied problems of technique and technology. No. 3 (323). (2017).

18. Chernyshov, E.A., Romanov, A.D., Kaverin, B.S., Varyukhin, V.A., Ob’edkov, A.M., Semenov, N.M. Development of Technology for Preparing Composite Material Based on Aluminum Strengthened with Hollow Ceramic Microspheres Metallurgist Volume 62, Issue 11-12, (2019) 